\title{
A Concise Synthesis of the 1,6-Disubstituted Eudesmane Sesquiterpene Carbon Skeleton
}

\author{
Ygor Willian Vieira, Joanita Nakamura, Fernanda Gadini Finelli, Ursula Brocksom and \\ Timothy John Brocksom* \\ Departamento de Química, Universidade Federal de São Carlos, 13565-905 São Carlos-SP, Brazil
}

\begin{abstract}
Descrevemos uma síntese do esqueleto carbônico dos sesquiterpenos do grupo eudesmano substituído nos carbonos 1 e 6, que se baseia na versão multicomponente da reação de Diels-Alder.

We report a synthesis of the 1,6-disubstituted eudesmane sesquiterpene carbon skeleton, based upon a multicomponent Diels-Alder reaction.
\end{abstract}

Keywords: eudesmane, sesquiterpene, multicomponent reaction, Diels-Alder, thymoquinone

\section{Introduction}

The eudesmane sesquiterpenes are an important class of natural products, with relevant biological activities. ${ }^{1}$ Although these compounds can be substituted at practically all the carbon atoms, there is current interest for examples substituted at both C-1 and C-6 (see Schemes 1 and 2). In this short report we present a new methodology for the concise synthesis of the 1,6-disubstituted eudesmane carbon skeleton.

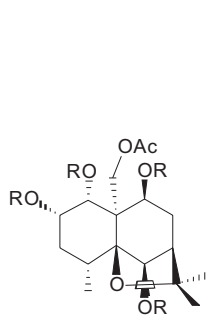

A

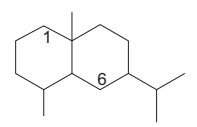

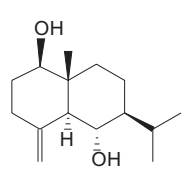

B

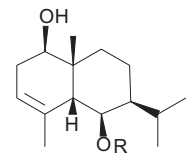

C
$\mathrm{R}=\mathrm{H}$ or ester groups

Scheme 1.

The total synthesis of these natural products is not a new challenge ${ }^{2}$ but the construction of appropriately substituted decalin carbon skeletons is still a relevant synthetic task. Recently, many new examples of eudesmane sesquiterpenes have been isolated from natural sources and several new synthetic methodologies have been described. Among the new structures which have been determined, the following are of special interest for

*e-mail: brocksom@terra.com.br our synthetic study (Scheme 1), and several possess relevant biological activities. The agarofurans, as exemplified by structure $\mathbf{A},{ }^{3}$ are replete with biological activities as shown by further examples. ${ }^{4}$ The simpler eudesmanes $\mathbf{B}$ and $\mathbf{C}$ have also been isolated, with more examples recorded in the literature..$^{5-7}$

Scheme 2 presents some eudesmanes which have been synthesized recently, and taken together Schemes 1 and 2 demonstrate the current interest in these apparently simple structures. The synthetic challenges involve the construction of the decalin bicyclic array in both transand cis-ring fusions, with provision for the incorporation of functional group substitutions at several of the ring carbon atoms. The older synthetic strategy involves the Robinson ring annulation sequence, ${ }^{2}$ with no provision for substitution at C-1 without lengthy and low yielding oxidations. The newer strategies include cationic cyclization to $\mathbf{D},{ }^{8}$ aldol cyclization to $\mathbf{E},{ }^{9}$ tricarbonylchromium dearomatization and aldol cyclization to $\mathbf{F},{ }^{10}$ and biomimetic ionic cyclization to $\mathbf{G} .{ }^{11}$

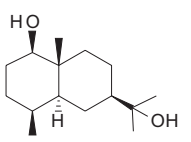

D

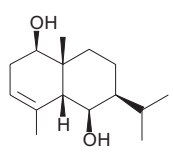

E

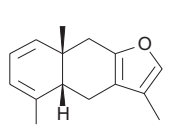

$\mathbf{F}$

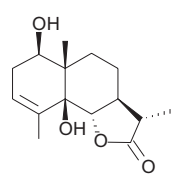

G
Scheme 2.

We have already established such a route based upon the Diels-Alder reaction of thymoquinone (2) with a 1-silyloxy-4-methyl-butadiene $\mathbf{4}$ as shown in Scheme 3. ${ }^{12}$ The dienophile thymoquinone (2) is a para-menthane monoterpene readily available in multi-gram quantities by 
oxidation of thymol (1). ${ }^{13}$ The diene component $\mathbf{4}$ can be prepared by reaction of commercially available trans-2pentenal (3) with tert-butyldimethylsilyl triflate, which in turn is prepared from commercial tert-butyldimethylsilyl chloride and triflic acid. ${ }^{14}$ The isomeric mixture of 1-TBSO4-methyl-butadienes $\mathbf{4}$ undergoes the Diels-Alder reaction with thymoquinone (2) in both thermolytic and zinc chloride catalyzed conditions, leading to the required 1-substituted eudesmane carbon skeleton $\mathbf{5}$. The procedure suffers from certain practical inconveniencies which detract from application on a multi-gram scale, with regard to the preparation of the diene 4 . The TBS triflate preparation requires previous distillation of the triflic acid and then reaction with the TBS chloride, and then immediate reaction with the trans-2-pentenal (3). The cycloaddition reaction is best performed with zinc chloride catalysis which also requires previous purification of the catalyst. The overall yield under these conditions is a very respectable $59 \%$ but it should be mentioned that we use the diene $\mathbf{4}$ in quite considerable molar excess (usually about seven molar equivalents) with respect to the much more readily available dienophile thymoquinone (2).

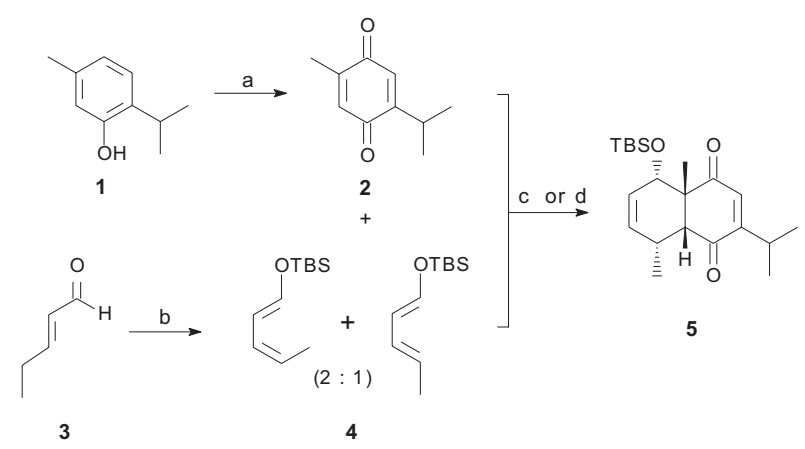

Scheme 3. Reagents and conditions; a) $\mathrm{O}_{2}, \mathrm{CO}$ (Salen) $)_{2}, \mathrm{DMF} / \mathrm{H}_{2} \mathrm{O} 85 \%$; b) TBSOTf, $\mathrm{Et}_{3} \mathrm{~N}, \mathrm{CH}_{2} \mathrm{Cl}_{2}$, reflux, $4 \mathrm{~h}, 70 \%$; c) reflux in toluene, $71 \mathrm{~h}$, $54 \%$; d) $\mathrm{ZnCl}_{2}, \mathrm{CH}_{2} \mathrm{Cl}$, rt, $27 \mathrm{~h}, 84 \%$

\section{Results and Discussion}

We now describe a multicomponent version of the Diels-Alder reaction of thymoquinone (2) which allows direct access to the same carbon skeleton containing substitutions at both the C-1 and C-6 carbon atoms. ${ }^{15-17}$ The diene component is also prepared from trans-2pentenal (3) but in a much easier fashion.

Thymoquinone (2) is reacted with trans-2-pentenal (3) and acetamide, catalytic para-toluenesulphonic acid, under reflux in an appropriate solvent for 24 hours. Acetamide can be exchanged for benzamide with practically no difference with regard to the yield.

These conditions are believed to favor a series of equilibriums including protonations, nucleophilic addition of the amide to trans-2-pentenal (3), elimination of water, and proton shifts, thus generating the desired 1-amido-4methyl-butadiene $\mathbf{6}$ in situ. Diels-Alder cycloaddition with thymoquinone (2) then produces the cycloadducts $\mathbf{7 a}$ and 7b as shown in Scheme 4.<smiles>CC/C=C/C(C)=O</smiles>

3
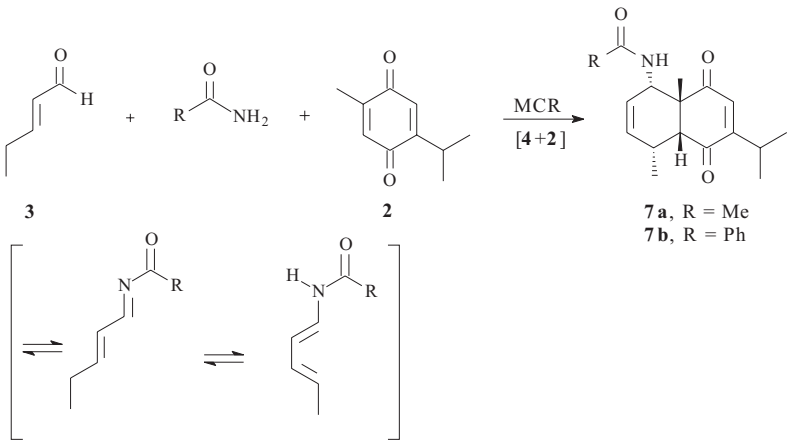

$7 \mathrm{a}, \mathrm{R}=\mathrm{Me}$ $7 \mathbf{b}, \mathrm{R}=\mathrm{Ph}$

Scheme 4. Reagents and conditions; see Table 1

These multicomponent reactions were studied under various conditions, with both acetamide and benzamide, and using $N$-methyl-pyrrolidone (NMP), dimethylformamide (DMF) and toluene as solvent (see Table 1). ${ }^{15,16,18}$ Initially we used the polar aprotic solvent NMP which should favor the equilibrium reactions and their polar transition states. For equal reasons DMF was used and showed similar reactivity although with slightly lower yields. Surprisingly, toluene gave much better yields and also allowed us to use a Dean-Stark separator for removal of the water formed during the reaction. This procedure avoids the use of acetic anhydride with NMP and DMF as solvents.

The product was identified by the usual spectroscopic and analytical methods, and also by comparison with other cycloadducts obtained in our laboratory, principally the OTBS analogue $\mathbf{5}$ whose structure has been determined by single crystal X-ray diffraction. ${ }^{12}$

Table 1. The multicomponent Diels-Alder reactions

\begin{tabular}{lccc}
\hline Entry & $\mathrm{R}$ & Solvent & Yield/(\%) \\
\hline 1 & $\mathrm{Me}$ & $\mathrm{NMP}^{\mathrm{a}}$ & 45 \\
2 & $\mathrm{Me}$ & $\mathrm{DMF}^{\mathrm{b}}$ & 35 \\
3 & $\mathrm{Me}$ & Toluene $^{\mathrm{c}}$ & 70 \\
4 & $\mathrm{Ph}$ & $\mathrm{NMP}^{\mathrm{a}}$ & 48 \\
5 & $\mathrm{Ph}$ & $\mathrm{DMF}^{\mathrm{b}}$ & 32 \\
6 & $\mathrm{Ph}$ & Toluene $^{\mathrm{c}}$ & 75 \\
\hline
\end{tabular}

${ }^{\mathrm{a}} \mathrm{Ac}_{2} \mathrm{O}, \mathrm{PTSA}, 90^{\circ} \mathrm{C}, 24 \mathrm{~h},{ }^{\mathrm{b}} \mathrm{Ac}_{2} \mathrm{O}, \mathrm{PTSA}, 90^{\circ} \mathrm{C}, 24 \mathrm{~h},{ }^{\mathrm{cPTSA}}, 120^{\circ} \mathrm{C}, 24 \mathrm{~h}$.

\section{Conclusions}

We have thus demonstrated a very concise multicomponent version of the Diels-Alder reaction between thymoquinone (2), trans-2-pentenal (3), acetamide (or 
benzamide) in the presence of PTSA, in toluene under reflux with water removal. The yields are $70 \%$ and $75 \%$ respectively thus allowing access to multi-gram quantities of important synthetic intermediates $\mathbf{7 a}$ and 7b for 1,6-disubstituted eudesmane sesquiterpenes.

\section{Experimental}

\section{General}

${ }^{1} \mathrm{H}$ and ${ }^{13} \mathrm{C}$ NMR spectra were obtained on a Bruker DRX-400 spectrometer at 400 and $100 \mathrm{MHz}$, and on a Bruker ARX-200 spectrometer at 200 and $50 \mathrm{MHz}$ respectively, with $\mathrm{CDCl}_{3}$ as solvent. Chemical shifts are in ppm downfield from a tetramethylsilane internal standard. Infrared spectra were recorded on Bomen Michelson model 102 FTIR or Hartman \& Braun MB, and the most intense or representative bands are reported (in $\mathrm{cm}^{-1}$ ). Microanalyses were determined on an EA1108 Fisons CHNS-O model analyzer. Melting points were determined on a Micro Química model APF 301 apparatus and are uncorrected. Radial chromatography was performed on a Chromatotron ${ }^{\circledR}$ model 8924 with 2 mm plates of silica gel 60, PF 254 with calcium sulphate, E. Merck 7749. Gas liquid chromatographic analyses were performed on a Shimadzu GC-17A, equipped with a DB-1 capillary column $(0.25 \mathrm{~mm} \times 30 \mathrm{~m})$ and using nitrogen as carrier gas. Solvents and reagents were used directly from the manufacturer, or purified when required by standard procedures.

rac-(1R,6R,7R,10S)-10-Acetamido-1,7-dimethyl-4isopropyl-bicyclo [4.4.0] 3,8-decadienedione-2,5 (7a)

\section{In N-methyl-pyrrolidone (NMP)}

To a solution of thymoquinone (2) (164 mg, $1 \mathrm{mmol}$ ) in NMP (2 mL) was added trans-2-pentenal (3) $(0.15 \mathrm{~mL}$, $1.5 \mathrm{mmol}$ ), acetamide ( $89 \mathrm{mg}, 1.5 \mathrm{mmol}$ ), acetic anhydride $(0.14 \mathrm{~mL}, 1.5 \mathrm{mmol})$ and para-toluenesulphonic acid (a small crystal). The solution was refluxed $\left(90{ }^{\circ} \mathrm{C}\right)$ under a nitrogen atmosphere for 24 hours. A saturated aqueous solution of $\mathrm{NH}_{4} \mathrm{Cl}(5 \mathrm{~mL})$ was added and the mixture extracted continuously for two days with hexane. The organic phase was washed with aqueous $\mathrm{NaHCO}_{3}$ and dried over anhydrous $\mathrm{Na}_{2} \mathrm{SO}_{4}$. The solution was concentrated on a rotary evaporator at reduced pressure, and the crude product was chromatographed on silica gel with hexane/ethyl acetate (7:3) as eluent to obtain 130 $\mathrm{mg}$ of the pure product $7 \mathbf{a}$ (yield $45 \%$ ). mp $112-113{ }^{\circ} \mathrm{C}$. IR (KBr) $v_{\max } / \mathrm{cm}^{-1}: 3400 ; 3030 ; 2970 ; 1750 ; 1680 ; 1611$; 1040. ${ }^{1} \mathrm{H}$ NMR $\left(400 \mathrm{MHz}, \mathrm{CDCl}_{3}\right) \delta: 0.82(\mathrm{~d}, J 7.6 \mathrm{~Hz}$,
$3 \mathrm{H}) ; 1.14(\mathrm{~d}, J 6.8 \mathrm{~Hz}, 6 \mathrm{H}) ; 1.38(\mathrm{~s}, 3 \mathrm{H}) ; 2.04$ (s, 3H); 2.73 (m, 1H); 2.99 (dhept, $J$ 1.0, $6.8 \mathrm{~Hz}, 1 \mathrm{H}) ; 3.18$ (d, $J$ $8.2 \mathrm{~Hz}, 1 \mathrm{H}) ; 4.57$ (m, 1H); 5.52 (dt, J 1.8, $10.1 \mathrm{~Hz}, 1 \mathrm{H})$; 5.59 (dt, $J 2.8,10.1 \mathrm{~Hz}, 1 \mathrm{H}) ; 6.41(\mathrm{~d}, J 1.0 \mathrm{~Hz}, 1 \mathrm{H}) ; 7.12$ (d, J $9.9 \mathrm{~Hz}, 1 \mathrm{H}) .{ }^{13} \mathrm{C} \mathrm{NMR}\left(100 \mathrm{MHz}, \mathrm{CDCl}_{3}\right) \delta: 19.0$, 21.1, 23.0, 23.5, 25.4, 26.7, 31.0, 49.6, 50.8, 57.7, 127.9, 131.2, 133.5, 158.9, 169.7, 199.7, 203.8; Analysis Calc. for $\mathrm{C}_{17} \mathrm{H}_{23} \mathrm{NO}_{3}$ : C 70.56; $\mathrm{H} 8.01 ; \mathrm{N} 4.84$; Found: C 70.22; $\mathrm{H} 8.40 ; \mathrm{N} 4.81$.

\section{In dimethylformamide (DMF)}

The reaction was repeated as above, exchanging NMP for DMF ( $2 \mathrm{~mL}$ ) for the same time at the same temperature under a nitrogen atmosphere. The reaction mixture was treated with water $(5 \mathrm{~mL})$ and the product extracted with diethyl ether $(3 \times 5 \mathrm{~mL})$. The organic phase was washed with a $10 \% \mathrm{HCl}$ solution, with water, and then dried over anhydrous $\mathrm{Na}_{2} \mathrm{SO}_{4}$. The solution was concentrated on a rotary evaporator at reduced pressure, and the crude product chromatographed on silica gel with hexane/ethyl acetate (8:2) as eluent, to give $101 \mathrm{mg}$ of the cycloadduct $7 \mathbf{a}$ (yield $35 \%$ ).

\section{In toluene}

The reaction was repeated essentially as before, but in toluene $(3 \mathrm{~mL})$ and without acetic anhydride. The mixture was refluxed under a nitrogen atmosphere at $120{ }^{\circ} \mathrm{C}$ for 24 hours with a Dean-Stark water separator connected. The solution was concentrated on a rotary evaporator, and the crude product chromatographed on silica gel with hexane/ethyl acetate $(9: 1)$ as eluent to give $202 \mathrm{mg}$ of the pure product 7a (yield 70\%).

rac-(1R,6R, 7R, 10S)-10-Benzamido-1,7-dimethyl-4isopropyl-bicyclo [4.4.0] 3,8-decadienedione-2,5 (7b)

\section{In N-methyl-pyrrolidone (NMP)}

The reaction was performed as above with exchange of the acetamide for benzamide (182 $\mathrm{mg}, 1.5 \mathrm{mmol}$ ), furnishing $162 \mathrm{mg}$ of the pure product $\mathbf{7 b}$ after column chromatography on silica gel (yield 48\%). mp 107$109{ }^{\circ} \mathrm{C}$. IR (KBr) $v_{\max } / \mathrm{cm}^{-1}: 1748,1677,1605,1510$, 1483. ${ }^{1} \mathrm{H}$ NMR (400 MHz, $\mathrm{CDCl}_{3}$ ) $\delta: 0.88(\mathrm{~d}, J 7.2 \mathrm{~Hz}$, $3 \mathrm{H}) ; 1.13(\mathrm{~d}, J 6.2 \mathrm{~Hz}, 6 \mathrm{H}) ; 1.45(\mathrm{~s}, 3 \mathrm{H}) ; 2.75-2.78(\mathrm{~m}$, 1H); 3.00 (hept, $J 6.2 \mathrm{~Hz}, 1 \mathrm{H}) ; 3.25$ (d, J $7.4 \mathrm{~Hz}, 1 \mathrm{H})$; $4.79(\mathrm{~d}, J 9.5 \mathrm{~Hz}, 1 \mathrm{H}) ; 5.64(\mathrm{~s}, 2 \mathrm{H}) ; 6.43(\mathrm{~s}, 1 \mathrm{H}) ; 7.4-$ $7.5(\mathrm{~m}, 3 \mathrm{H}) ; 7.82(\mathrm{~d}, J 6.5 \mathrm{~Hz}, 2 \mathrm{H}) ; 7.96(\mathrm{~d}, J 9.5 \mathrm{~Hz}$, 1H). ${ }^{13} \mathrm{C}$ NMR (100 MHz, $\left.\mathrm{CDCl}_{3}\right) \delta: 19.4,21.2,21.4$, 25.9, 27.1, 31.5, 50.0, 51.7, 57.7, 127.0, 127.7, 128.6, 131.6, 131.8, 133.8, 158.2, 159.0, 167.0, 200.1, 204.6; Analysis Calc. for $\mathrm{C}_{22} \mathrm{H}_{25} \mathrm{NO}_{3}$ : C 75.19; $\mathrm{H} 7.17$; N 3.99; Found: C 74.85; H 7.53; N 4.06. 


\section{In $D M F$}

The reaction was performed as above, with exchange of acetamide for benzamide (182 $\mathrm{mg}, 1.5 \mathrm{mmol})$. The pure product $\mathbf{7 b}$ was obtained (108 $\mathrm{mg}, 32 \%$ yield) after column chromatography on silica gel.

\section{In toluene}

The reaction was repeated essentially as above, with exchange of acetamide for benzamide (182 mg, $1.5 \mathrm{mmol}$ ). The pure product $\mathbf{7 b}$ was obtained $(253 \mathrm{mg}, 75 \%$ yield) after column chromatography.

\section{Acknowledgments}

The authors thank FAPESP, CNPq and CAPES for financial support and fellowships.

\section{References}

1. Fraga, B. M.; Nat. Prod. Rep. 2005, 22, 465; for an exhaustive review on the eudesmane sesquiterpenes see; Wu, Q-X.; Shi, Y-P.; Jia, Z-J.; Nat. Prod. Rep. 2006, 23, 699.

2. Heathcock, C. H.; Graham, S. L.; Pirrung, M. C.; Plavac, F.; White, C. T. In The Total Synthesis of Natural Products, ApSimon, J., ed.; J. Wiley: New York, 1983, vol. 5.

3. Munõz-Martínez, F.; Mendoza, C. R.; Bazzocchi, I. L.; Castanys, S.; Jiménez, I. A.; Gamarro, F.; J. Med. Chem. 2005, 48, 4266.

4. Morikawa, T.; Kishi, A.; Pongpiriyadacha, Y.; Matsuda, H.; Yoshikawa, M.; J. Nat. Prod. 2003, 66, 1191; Núñez, M. J.; Guadaño, A.; Jiménez, I. A.; Ravelo, A. G.; González-Coloma, A.; Bazzocchi, I. L.; J. Nat. Prod. 2004, 67, 14.

5. Zhang, H-J.; Tan, G. T.; Santarsiero, B. D.; Mesecar, A. D.; Hung, N. V.; Cuong, N. M.; Soejarto, D. D.; Pezzuto, J. M.; Fong, H. H. S.; J. Nat. Prod. 2003, 66, 609.

6. Cheng, Z-H.; Wu, T.; Bligh, S. W. A.; Bashall, A.; Yu, B.; J. Nat. Prod. 2004, 67, 1761.
7. Amaro-Luis, J. M.; Ramirez, I.; Delgado-Méndez, P.; Jorge, Z. D.; J. Braz. Chem. Soc. 2002, 13, 352; Chang, J.; Xuan, LJ.; Xu, Y-M.; Zhang, J-S.; J. Nat. Prod. 2001, 64, 935; Appendino, G.; Cravotto, G.; Sterner, O.; Ballero, M.; J. Nat. Prod. 2001, 64, 393; Sun, Z.; Chen, B.; Zhang, S.; Hu, C.; J. Nat. Prod. 2004, 67, 1975.

8. Zhang, Z.; Li, W-D. Z.; Li, Y.; Org. Lett. 2001 3, 2555.

9. Zheng, G.; Chen, J.; Fang, L.; Tang, Z.; Li, Y.; Tetrahedron 2004, 60, 6177.

10. Kündig, E. P.; Cannas, R.; Laxmisha, M.; Ronggang, L.; Tchertchian, S.; J. Am. Chem. Soc. 2003, 125, 5642.

11. Li, W-D. Z.; Gao, Z-H.; Org. Lett. 2005, 7, 2917.

12. Brocksom, T. J.; Corrêa, A.G.; Naves, R. M.; Silva Jr., F.; Catani, V.; Ceschi, M. A.; Zukerman-Schpector, J.; Toloi, A. P.; Ferreira, M. L.; Brocksom, U. In Organic Synthesis: Theory and Applications; Hudlicky, T., ed.; JAI/Elsevier Science: London, 2001, vol. 5, pp. 39-87.

13. Dockal, E. R.; Cass, Q. B.; Brocksom, T. J.; Brocksom, U.; Corrêa, A. G.; Synth. Commun. 1985, 15, 1033.

14. White, J. D.; Shin, H.; Kim, T. S.; Cutshall N. S.; J. Am. Chem. Soc. 1997, 119, 2404.

15. Beller, M.; Von Wangelin, A. J.; Neumann, H.; Gördes, D.; Spannenburg, A.; J. Am. Chem. Soc. 2001, 123, 8398; Beller, M.; Von Wangelin, A. J.; Neumann, H.; Gördes, D.; Spannenburg, A.; Baumann, W.; Tetrahedron 2002, 58, 2381.

16. Beller, M.; Von Wangelin, A. J.; Neumann, H.; Gördes, D.; Spannenburg, A.; Org. Lett. 2001, 3, 2895.

17. Brocksom, T. J.; Nakamura, J.; Ferreira, M. L.; Brocksom, U.; J. Braz. Chem. Soc. 2001, 12, 597.

18. Beller, M.; Von Wangelin, A. J.; Neumann, H.; Gordes, D.; Klaus, S.; Hübner, S.; Strübing, D.; Adv. Synth. Catal. 2004, 346, 970.

Received: August 28, 2006

Web Release Date: March 30, 2007

FAPESP helped in meeting the publication costs of this article. 